\title{
EXTERNAL EAR: MORPHOLOGICAL AND MORPHOMETRIC STUDY IN NORTH INDIAN MALES AND FEMALES
}

\author{
Vijay Laxmi ${ }^{1}$, Palak ${ }^{2}$, Sharma Nidhi ${ }^{* 3}$, JS Kullar ${ }^{4}$, RK Sharma ${ }^{5}$. \\ 1,2,4,5 Department of Anatomy, Government Medical College, Amritsar, Punjab, India. \\ ${ }^{*}$ Department of Pharmacology, Government Medical College, Amritsar, Punjab, India.
}

\section{ABSTRACT}

Introduction: In humans, ear is the most defining feature of the face and its structure shows the signs of age and sex. The understanding of various dimensions of external ear with regards to different age and sex is necessary for correct reconstruction, forensic purposes and to determine accurately the position and orientation of auricular framework. This will also serve as a baseline to guide surgeons involved in the management of cases of the external ear.

Aim: This study aimed at determining the mean values of the different morphometric measurements from the right and left ears and at giving information about sex related dimensions of ear and right and left symmetry.

Materials and Methods: The present study was carried out on 100 medical students which consisted of 50 Males and 50 Females of age group 18-25 years of Government Medical College, Amritsar. All the parameters were taken by using standard digital vernier calliper which is capable of measuring to the nearest of $0.01 \mathrm{~mm}$.

Results and Conclusion: The shape of the ear was found to be oval in most of the specimens. The TEH and TEW have higher values in males than females. The left ear indices were found to be greater than the right ones in female subjects, but same on both sides in male subjects. An observation was made that on the right side, females have higher LH than males. TL was also found to be greater in males when compared with females.

KEY WORDS: Total Ear Height, Total Ear Width, Ear Index, Lobule Height, Lobule Width, Lobule Index, Tragus Length.

Address for Correspondence: Dr.Nidhi Sharma, Department of Pharmacology, Government Medical College, Amritsar, Punjab, India. E-Mail: palakchhabra48@gmail.com

\begin{tabular}{|l|l|}
\multicolumn{3}{|c|}{ Access this Article online } \\
\hline $\begin{array}{l}\text { Quick Response code } \\
\text { Web site: International Journal of Anatomy and Research } \\
\text { ISSN 2321-4287 } \\
\text { www.ijmhr.org/ijar.htm }\end{array}$ \\
\cline { 2 - 3 }
\end{tabular}

\section{INTRODUCTION}

In humans, ear is the most defining feature of the face and its structure shows the signs of age and sex [1]. Next to fingerprints, the external ear constitutes the most unique design, characteristic features and peculiarities for the purpose of identification [2]. Its size, shape and spatial location on the face are important from an aesthetic point of view [3].

The anatomical appearance of the auricle varies from individual to individual and between ethnic races [4]. The shape, size and orientation of each external ear are specific [5]. Features of auricle have been recognized as an important anthropological variable for studying racial variability and for few genetic abnormalities at an early stage of life [6]. The use of ear morphology and the variations created by its anatomical form are implemented principally for identification of perpetrators and it provides data procedures for inclusion and exclusion of persons for identification purpose in relation to 
criminal activity [7]. Physicians have used the auricle as a harbinger of underlying pathology, psychologists as a clue of personality disorder, criminologists as a means of racial discrimination [8].

Imhofer (1906) studied the possibility of using ear characteristics for assessing familial relationships, because the morphology of ears tends to be hereditary [9].

Ikeda M et al (2001) concluded that larger values were obtained for males than females in almost all age groups. Rapid growth was observed until late teenage and significant growth continued thereafter until advanced age. It was concluded that age associated changes appear to continue during adulthood [10]. Jung and Jung (2003) surveyed the dimensions and characterstics of Korean ears and found that age, gender, and different ethnic populations were determinants of ear dimensions [11]. In the study conducted by Barut et al (2006), the left ear indices were found to be significantly higher than the right ear indices for all the subjects [12].

The present study was designed to attain a complete knowledge about morphology and morphometry of external ear.

\section{MATERIALS AND METHODS}

The present study was carried out on 100 medical students which consisted of 50 Males and 50 Females of age group 18-25 years of Government Medical College, Amritsar. Thus, the study consists of 200 ears, 100 from the right side and 100 from the left side. The subjects were labelled from 1-50 as females and 51-100 males. Subjects with malformation, deformity, inflammation, trauma, surgical scars or any other abnormality of the ears were excluded because of their unsuitability for this study.

Each subject was made to sit in a natural head position on a chair with a backrest and positioned the head such that the subject looks straight forward with lower border of the eye sockets in the same plane as the external auditory meatuses- Frankfurt horizontal plane. Bilateral measurements of auricle were taken. All the parameters were taken by using standard digital vernier calliper which is capable of measuring to the nearest of $0.01 \mathrm{~mm}$. For each subject, the measurements were carried out twice to ascertain accuracy and the arithmetical mean of the two measurements was recorded on the proforma.

Following parameters of external ear were taken:

Total Ear height: Uppermost point of pinna to the lowermost point of lobule.

Ear width: From root of the ear to maximum convexity of the helix.

Ear index : ear width/ear height $\times 100$

Lobular height: From lower point of attachment of external ear to the head to the caudal extension of the ear lobe free margin (subaurale)

Lobule width: From the most caudal attachment of the ear lobule to the head and to the outermost maximum transverse width of the ear lobule.

Lobule index: Lobule width/lobule height $\times 100$ Tragus length: From tragion to intertragic incisures.

Fig. 1: Showing the parameters of external ear.

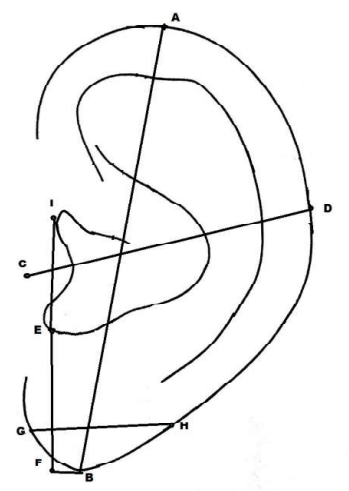

AB- Total Ear Height , CD- Total Ear Width, EF- Lobule Height GHLobule Width, IE-Tragus Length All the measurements were taken in $\mathrm{cm}$.

\section{OBSERVATIONS AND RESULTS}

Table 1: Showing the Comparisons of Parameters in both genders.

\begin{tabular}{|c|c|c|c|c|c|}
\hline \multirow{2}{*}{\multicolumn{2}{|c|}{ Parameters }} & \multicolumn{2}{|c|}{ Males } & \multicolumn{2}{|c|}{ Females } \\
\hline & & \multirow{2}{*}{$\frac{\text { Mean } \pm S D}{6.2 \pm 0.44}$} & \multirow{2}{*}{$\begin{array}{c}\text { Range } \\
5.20-8.01\end{array}$} & \multirow{2}{*}{$\frac{\text { Mean } \pm S D}{5.73 \pm 0.35}$} & \multirow{2}{*}{$\begin{array}{c}\text { Range } \\
4.87-6.62\end{array}$} \\
\hline & $\mathbf{R}$ & & & & \\
\hline ILก & $\mathrm{L}$ & $6.18 \pm 0.40$ & $5.20-7.86$ & $5.73 \pm 0.32$ & 5.04-6.39 \\
\hline \multirow{2}{*}{ TEW } & $\mathbf{R}$ & $3.42 \pm 0.28$ & $2.82-4.10$ & $3.2 \pm 0.27$ & $2.83-4.01$ \\
\hline & $\mathrm{L}$ & $3.40 \pm 0.29$ & 2.69-4.05 & $3.2 \pm 0.27$ & $2.60-3.90$ \\
\hline \multirow{2}{*}{ El } & $R$ & $55.2 \pm 4.3$ & $43.90-64.10$ & $56.07 \pm 4.13$ & $48.63-67.60$ \\
\hline & $\mathrm{L}$ & $55.2 \pm 4.8$ & $41.90-66.50$ & $56.9 \pm 4.6$ & $44.90-67.10$ \\
\hline \multirow{2}{*}{ LH } & $\mathbf{R}$ & $1.21 \pm 0.20$ & $0.79-1.76$ & $1.23 \pm 0.22$ & $0.74-2.00$ \\
\hline & $\mathrm{L}$ & $1.22 \pm 0.20$ & $0.80-1.90$ & $1.20 \pm 0.23$ & $0.74-2.15$ \\
\hline \multirow{2}{*}{ LW } & $R$ & $1.71 \pm 0.19$ & $1.28-2.41$ & $1.64 \pm 0.31$ & $0.72-2.39$ \\
\hline & $\mathrm{L}$ & $1.69 \pm 0.18$ & $1.17-2.04$ & $1.69 \pm 0.31$ & $1.22-2.64$ \\
\hline \multirow{2}{*}{ LI } & $\mathbf{R}$ & $143.5 \pm 21.3$ & 104-191.1 & $139.3 \pm 26.7$ & $59.6-200.8$ \\
\hline & $\mathrm{L}$ & $142.7 \pm 17.8$ & $113-186.5$ & $144.4 \pm 28.1$ & $92.3-221.4$ \\
\hline \multirow{2}{*}{$\mathrm{TL}$} & $\mathbf{R}$ & $1.60 \pm 0.16$ & $0.84-1.96$ & $1.51 \pm 0.14$ & $1.08-1.94$ \\
\hline & L & $1.57 \pm 0.18$ & $0.87-1.97$ & $1.50 \pm 0.14$ & $1.28-1.97$ \\
\hline
\end{tabular}




\section{DISCUSSION}

Shape: In the present study, it was found that $41(82 \%)$ males and $43(86 \%)$ females have oval shape, 8 males (16\%) and $6(12 \%)$ females have round shape while $1(2 \%)$ male and $1(2 \%)$ female have triangular shape (both on right side as well as left). The use of morphology of shape can be used for establishing identity of persons.

Total Ear Height (TEH): The range of the TEH on the right side was found to be $5.2-8.01 \mathrm{~cm}$ in males and 4.87-6.62 cm in females with a mean height of $6.20 \pm 0.44 \mathrm{~cm}$ in males and $5.73 \pm 0.35$ $\mathrm{cm}$ in females. The same when compared to the left side was found to be $5.2-7.86 \mathrm{~cm}$ in males and $5.04-6.39 \mathrm{~cm}$ in females with a mean value of $6.18 \pm 0.40 \mathrm{~cm}$ and of $5.73 \pm 0.32 \mathrm{~cm}$ respectively. It was observed that the mean height of right ear was greater than the left ear in males. The TEH serves as an important characterstic in evaluation of congenital anomalies.

Total Ear Width (TEW): From the above table, it is clear that the mean width of ear in males was found to be $3.42 \pm 0.28 \mathrm{~cm}$ (range $2.82-4.01$ ) on right side and $3.40 \pm 0.29 \mathrm{~cm}$ (range 2.69-4.05 ) on left side. While in females, the mean was $3.2 \pm 0.27 \mathrm{~cm}$ on both sides but the range varied from $2.83-4.01 \mathrm{~cm}$ on right side, and $2.60-3.90$ $\mathrm{cm}$ on left side. It was observed that the the males have greater values than females.

Ear Index (EI): The mean of El in males was found to be 55.2 (both on right side as well as left) while in females it was found $56.07 \pm 4.13$ on right side and $56.9 \pm 4.6$ on left side. The range of $\mathrm{EI}$ in males varies from $43.90-64.10$ on right side and 41.90-66.50 on left side. In females it ranges from 48.63-67.60 on right side and 44.90-67.10 on left side. On comparing, it is clear that the left ear indices were found to be greater than the right ones in female subjects, but same on both sides in male subjects.

Lobule Height (LH): The LH in males varied from $0.79-1.76 \mathrm{~cm}$ on right side and $0.80-1.90 \mathrm{~cm}$ on left side with a mean height of $1.21 \pm 0.20 \mathrm{~cm}$ and $1.22 \pm 0.20$ respectively. In females, the $\mathrm{LH}$ showed a range of $0.74-2.00 \mathrm{~cm}$ on right side and $0.74-2.15$ on left side with a mean value of $1.23 \pm 0.22 \mathrm{~cm}$ and $1.20 \pm 0.23 \mathrm{~cm}$.

Lobule Width (LW): In the present study, the mean LW on the right side was $1.71 \pm 0.19 \mathrm{~cm}$ in

males and $1.64 \pm 0.31 \mathrm{~cm}$ in females with a range of $1.28-2.41 \mathrm{~cm}$ and $0.72-2.39 \mathrm{~cm}$ respectively. The same when compared on left side was $1.69 \pm 0.18 \mathrm{~cm}$ in males and $1.69 \pm 0.31 \mathrm{~cm}$ in females with a range of 1.17-2.04 and 1.22-2.64 respectively. It was observed that the right LW was found to be greater than the left in males.

Lobu Le Index (LI): The mean LI on right side was $143.5 \pm 21.3$ (range 104-191.1) in males and $139.3 \pm 26.7$ (range 59.6-200.8) in females while on the left side it was $142.7 \pm 17.8$ (range 113186.5 ) in males and $144.4 \pm 28.1$ (range 92.3221.4) in females.

Tragus Length (TL): The mean and range of $T L$ in males was $1.60 \pm 0.16 \mathrm{~cm}$ (range 0.84-1.96) on right side and $1.57 \pm 0.18$ (range $0.87-1.97$ ) on left side. In females it was $1.51 \pm 0.14$ (range1.08-1.94) on right side and 1.50 \pm 0.14 (range1.28-1.97) on left side.

\section{CONCLUSION}

The shape of the ear was found to be oval in most of the specimens. It was observed that the mean height of right ear was greater than the left ear in males. TEW was found to be more in males. On comparing, it is clear that the left ear indices were found to be greater than the right ones in female subjects, but same on both sides in male subjects. It was observed that on the right side, females have higher $\mathrm{LH}$ than males. It may be due to additional weight, the earings put on the ear, and therefore affect the lobule height. The right LW was found to be greater than the left in males. The right lobule index was higher than the left in males while in case of females the left lobule index was higher than the right. Thus, the understanding of various dimensions of external ear with regards to different age and sex is necessary for correct reconstruction, forensic purposes and to determine accurately the position and orientation of auricular framework. This will also serve as a baseline to guide surgeons involved in the management of cases of the external ear.

\section{ABBREVIATIONS}

TEH -Total Ear Height

TEW - Total Ear Width

El - Ear Index

LH - Lobule Height,
LW - Lobule Width

LI - Lobule Index

TL - Tragus Length 


\section{Conflicts of Interests: None}

\section{REFERENCES}

[1]. Kalra D, Kalra A, Goel S. Anthrometric measurements of external ear: an in vivo study. Int J Enhanc Res Med Dent Care. 2015;2(3):10-6.

[2]. Iannarelli AV. Ear identification, forensic identification series, Fremont, California, Paramont Publishing Company.1989.

[3]. Ruma P, Singh P. Anthropometry of the normal human auricle: A study of adult Indian men. J Aesth Plast Surg. 2007;31:372-9.

[4]. Altmann F. Malformations of the auricle and external auditory meatus. Arch Otolaryngology. 1951;54:115-39.

[5]. Shireen S, Vrushali P. Anthropometric Measurements of Human External Ear. Journal of Evolution of Medical and Dental Sciences 2015;59(4):10333-8.

[6]. Singh P, Ruma P. Anthropological study of human auricle. Journal of Indian Academy of Forensic Medicine. 2006;28(2):46-8.
[7]. Verma K, Bhawana J, Kumar V. Morphological variation of ear for individual identification in forensic cases: a study of an Indian population. Res J Forensic Sci. 2014;2(1):1-8.

[8]. Natekar PE, De Souza FM, Demarking and identifying points- reliable criteria for determination of sex from external ear. Indian J Otol. 2012;18(1):24-6.

[9]. Imhofer R. Die Bedeutung der Ohrmuschel für die Feststellung der Identitä, Kriminalanthropologie und Kriminalistik. 1906;2:150-63.

[10]. Ito I, Ikeda M, Sueno K, Sugiura M, Suzuki S, Kida A. Anthropometric study on normal human auricle in Japan. Nippon Jibiinkoka Gakkai Kalho. 2001;104(2):165-74.

[11]. Jung S.H, Jung S.H, Surveying the dimensions and characterstics of Korean ears for the ergonomic design of ear-related products. Int. J. Ind. Ergon. 2003;31:361-73.

[12]. Barut C, Aktunc E. Anthropometric measurement of the external ear in a group of Turkish primary school students. Aesth Plast Surg 2006;30:255-9.

How to cite this article:

Vijay Laxmi, Palak, Sharma Nidhi, JS Kullar, RK Sharma. EXTERNAL EAR: MORPHOLOGICAL AND MORPHOMETRIC STUDY IN NORTH INDIAN MALES AND FEMALES. Int J Anat Res 2017;5(2.2):3866-3869. DOI: 10.16965/ijar.2017.206 